\title{
Optimization of Antibiotic Use in Hospitals - Antimicrobial Stewardship and the EU Project ABS International
}

\author{
Franz Allerberger Arno Lechner Agnes Wechsler-Fördös \\ Roland Gareis on behalf of ABS International \\ ABS-Group, Project Office, Roland Gareis Consulting, Vienna, Austria
}

\author{
Key Words \\ Antibiotics • Antimicrobials • Resistance $\cdot$ Stewardship • \\ Project
}

\begin{abstract}
Background: The problem of antimicrobial resistance requires common strategies at the European level. Methods: We report on an EU initiative fostering antibiotic $(A B)$ stewardship (ABS) in hospitals. Results: The project 'ABS International: implementing antibiotic strategies for appropriate use of antibiotics in hospitals in member states of the EU' started in September 2006 in Austria, Belgium, the Czech Republic, Germany, Hungary, Italy, Poland, Slovenia and Slovakia. A training program for national $A B S$ trainers was prepared and standard templates for $A B S$ tools ( $A B$ list, guidelines for $A B$ treatment and surgical prophylaxis, and $A B$-related organization) and valid process measures as well as quality indicators for $A B$ use were developed. Specific $A B S$ tools are being implemented in up to five health care facilities per country. Conclusion: ABS International is the first EU-funded initiative focusing on the implementation of structural measures in hospitals to promote the prudent use of $A B s$.

Copyright $\odot 2008$ S. Karger AG, Basel
\end{abstract}

The Members of ABS International are shown in the Appendix. (c) 2008 S. Karger AG, Basel

$0009-3157 / 08 / 0544-0260 \$ 24.50 / 0$

Fax +41613061234

E-Mail karger@karger.ch

www.karger.com
Accessible online at:

www.karger.com/che

\section{Antimicrobial Resistance - A Public Health Threat?}

Resistance to antimicrobial agents is a major public health problem $[1,2]$. If the current rate of increase in resistance to antimicrobial agents continues, it is possible we may see the return of the pre-antibiotic $(A B)$ era, i.e. the emergence of the post-AB era $[3,4]$. Although cooperative efforts between industry, academia and government to revive the pipeline of antimicrobial drugs have been proposed, we face a decade or longer during which introduction of new antimicrobial agents is expected to be minimal. Thus, to ensure that options exist for treating infections, it is imperative to make the best use of those antimicrobials that are currently available.

In 1998 the World Health Organization (WHO) issued an 'urgent' recommendation that all countries should ensure that measures be taken to develop national guidelines for $A B$ therapy. The importance of efforts was underlined by the European Union (EU) in Copenhagen in 1998 and in Visby in 2001. The council recommendation of November 15, 2001, on the prudent use of antimicrobial agents in human medicine (2002/77/EC) asks to establish or strengthen surveillance systems on antimicrobial resistance and on the use of antimicrobial agents, to implement control and preventive measures to support the prudent use of antimicrobial agents and contribute to limiting the spread of communicable disease (e.g. control

Univ. Prof. Dr. Franz Allerberger

Österreichische Agentur für Gesundheit und Ernährungssicherheit

Spargelfeldstrasse 191, AT-1220 Wien (Austria)

Tel. +4350555 35500, Fax +43 5055525802

E-Mail Franz.Allerberger@ages.at 
systems on good practice of marketing of antimicrobials or implementing hygiene and infection control standards in institutions), to promote education and training of health professionals on the problem of antimicrobial resistance and to inform the general public of the importance of prudent use of antimicrobial agents [5]. Projects of importance for antimicrobial resistance funded by DG SANCO in 2007 were, among others, the European Antimicrobial Resistance Surveillance System, the Scientific Evaluation on the Use of Antimicrobial Agents in $\mathrm{Hu}-$ man Therapy and the EU Committee on Antimicrobial Susceptibility Testing. In 2002, the WHO issued the Antimicrobial Resistance Fact Sheet No. 194 which named hospitals a critical component of the antimicrobial resistance problem worldwide (http://www.who.int/mediacentre/factsheets/fs194/en/print.html).

According to the WHO, the combination of highly susceptible patients, intensive and prolonged antimicrobial use, and cross-infection has resulted in nosocomial infections with highly resistant bacterial pathogens. Resistant hospital-acquired infections are expensive to control and extremely difficult to eradicate. Failure to implement simple infection control practices, e.g. hand washing and changing gloves before and after contact with patients, is a common cause of infection spread in hospitals throughout the world. Many patients with severe infections due to resistant pathogens acquired in the community also end up in hospital. On April 7, 2005, the 58th World Health Assembly called antimicrobial resistance a threat to global health security and - again - called for the rational use of medicines by prescribers and patients.

\section{Antimicrobial Stewardship}

The term steward is derived from Old English stigweard, combining 'stig' (i.e. hall) and 'weard' (i.e. keeper). The American Heritage Dictionary defines steward as follows: (1) A person who manages another's property, finances or other affairs. (2) A person in charge of the household affairs of a large estate, club, hotel or resort. (3) An officer on a ship in charge of provisions and dining arrangements. (4) An attendant on a ship or airplane. (5) A shop steward. Therefore serving as a steward means to manage and stewardship equals 'the managing of'. However, when one checks Google and finds more than 19 million hits for stewardship, it must be realized that the term is increasingly used for the assumption of responsibility for the welfare of the world - the inclination which

Antibiotic Stewardship: Presenting the

EU Project ABS International leads some part of the world to care for the whole, i.e. the practice of that inclination. Stewardship is the mantle under which many progressive causes operate - human rights, conservation, economic welfare, government reform and oversight, education health care, disaster relief, animal welfare, mental health and peace. Especially the term 'environmental stewardship' is widely used as a synonym for the responsibility for taking good care of resources in the interest of long-term sustainability. Longterm sustainability is increasingly found as the major focus of antimicrobial stewardship programs. Until recently, their focus has been on ensuring the proper use of antimicrobials to provide the best patient outcomes, lessen the risk of adverse effects and promote cost-effectiveness. Antimicrobial management programs have been pursuing such goals for decades, although the term stewardship has been applied only infrequently [6-8]. MacDougall and Polk [7] define an antimicrobial stewardship program as an ongoing effort by a health care institution to optimize antimicrobial use among hospitalized patients in order to improve patient outcomes, ensure costeffective therapy and reduce adverse sequelae of antimicrobial use (including antimicrobial resistance). In the upcoming future, the objective of mitigating antimicrobial resistance will be of paramount importance. Given that it will be impossible for any organization to implement all the recommendations at any time, the weakness of projects on antimicrobial stewardship is that they often do not provide advice on the key elements within the many issues involved.

\section{The Role of the Austrian ABS Initiative: From a Pilot Project to the ABS Program}

In recent years, the main activity regarding the $A B$ issue in Austria has been the ABS (Antibiotics Strategies) Project of the Federal Ministry for Social Security and Generations. As early as 1997, the project 'ABS Concept' was initiated, and from 1998 to 2000 the ABS Project was implemented. The objectives of the ABS Project were to analyze and to further develop the 'AB culture' in Austrian hospitals, to optimize $A B$ prophylaxis and $A B$ therapy in the treatment of patients, and to reduce both $A B$ resistance and the costs of $A B$ therapy. The 'Guidelines to Further Develop and Define Antibiotic Use in Hospitals' in the German language in 1998 and in English in 2000 were major outputs of the ABS Project, with a revision of the German guide in 2002 [9-11]. In September 2002, the project 'Optimization of Antibiotic Use in Hospitals' 
funded by the Austrian Structural Fund was launched. The objective of this project was to provide considerable assistance to Austrian hospitals in optimizing their antibiotic strategies. Counseling sessions on the implementation of technical and organizational aspects of the $A B$ strategies were held in more than 30 Austrian hospitals. After these two successful projects, the 'ABS Platform' was launched at the beginning of 2005 to carry on the ABS Initiative in Austria. The main activities of this platform are ABS Basic Training, ABS Advanced Training, ABS Consulting and ABS Audits, ABS Symposia and $\mathrm{ABS}$ research projects.

\section{The Project: ABS International}

In April 2005, the proposal 'implementing AB strategies for appropriate use of $\mathrm{ABs}$ in hospitals in member states of the European Union - ABS International' was presented to the EU Commission. The proposed project met Article 2.5 'Antimicrobial Resistance' of the second priority area of the work plan 2005 Health Threats of DG SANCO. The project partners were recruited from nine member states of the EU, namely Austria, Belgium, the Czech Republic, Germany, Hungary, Italy, Poland, Slovenia and Slovakia. They combine universities, public health institutions, hospitals, the so-called ABS expert group and the Austrian Federal Ministry of Health. The ABS expert group represents a temporary association of ten Austrian infectious disease physicians and clinical microbiologists and was constituted to provide the legal framework for the project settlement. The proposal was officially accepted by the EU Commission in September 2005; the first negotiation meeting was held in Luxembourg on October 26, 2005. The project started on September 1,2006 , and is supposed to have a 2 -year duration.

\section{Tools}

The spectrum of activities that can be considered antimicrobial stewardship under the broadest definition is large. Which measures are likely to have an impact on overall antimicrobial use or antimicrobial resistance? We present essential measures used within the project 'implementing $A B$ strategies for appropriate use of $A B s$ in hospitals in member states of the European Union - ABS International': $\mathrm{an} \mathrm{AB}$ list, a guide for $\mathrm{AB}$ treatment, $\mathrm{a}$ guide for surgical prophylaxis, tools to analyze consump- tion data and an $\mathrm{AB}$-related organization (AB officer and $A B$ management team).

\section{Antibiotic List}

Lists of ABs pertaining to the needs of a particular hospital are essential instruments for optimizing the use of ABs in institutions [12-17]. In Austria, the so-called drug committee has the legal obligation to draw up a list of medications (drug list) used in the respective hospitals, to adapt this list and to develop guidelines on procurement and handling of medicines. By law it has to include the hospital's chief medical officer, the head of the hospital pharmacy or a pharmacy consultant and one additional physician.

The following describes the goals and possible structuring of $A B$ lists:

Every hospital should draw up an AB list appropriate to the institution. This list should include information (active ingredients and trade names) about the ABs used in the hospital. Thereby restricted ABs can be distinguished from standard ones. For each $\mathrm{AB}$, standard dosages and the cost of therapy per day should be included. The $\mathrm{AB}$ list does not provide information regarding the choice of an $\mathrm{AB}$ appropriate for a particular indication. Ordering from the pharmacy is made easier since all medications used in a particular hospital are included in the list, taking pertinent drug resistance and also costs into consideration. The drug committee should base its decision to add a medication to the list following the proposal of the $A B$ officer (definition of $A B$ officer: see below). The list is drawn up by the $\mathrm{AB}$ officer in cooperation with a pharmacist specializing in ABs. The pharmacist usually negotiates the prices for the hospital; for generics, the least expensive product is ordered. Regular updates are necessary according to the state of drug resistance and according to the market situation. Changing drug resistance or market situation may require addition or ejection of certain antimicrobials. The ABs included in the $A B$ list should be limited to the minimum necessary to provide effective prophylaxis and therapy. The drugs included should be placed in categories, with restrictions on the use of certain agents based on special indications, width of spectrum, toxicity, costs, potential to be misused and propensity to promote the development of resistance. The Anatomical Therapeutic Chemical classification index is a compilation of systemic antibacterial specialties from the WHO listing and serves as a complete index from which the lists for the individual hospitals are to be drawn [18]. Every hospital develops a specific AB list, appropriate for its particular needs, based on the $A B$ list 
template provided. Classifications different from the one provided as template may be more suitable for certain clinical purposes. Organizing ABs according to indication, e.g. grouping together staphylococcal or pseudomonas compounds, has proven useful, as has placing oral ABs immediately after the respective parenteral products to facilitate switch therapy. The corresponding combination products could also be listed immediately thereafter. The lists should generally be drawn up taking into account the range of the medications required and the clinical orientation of the hospital or department with respect to the state of local $A B$ resistance. The AB list should be updated periodically and compliance with the $\mathrm{AB}$ list should be audited. The evidence base for the benefits of restricted lists is probably greater than for any other control [19]. AB cycling is an unproven strategy [6]. ESGAP - the European Study Group on Antibiotic Policies - requests: 'An antibiotic policy and formulary (limited list) should be created locally after widespread consultation and its implementation ensured by audit cycles. It should be regularly updated in the light of local resistance problems and availability of new drugs' [20].

\section{Guide for Antibiotic Treatment}

A key element in encouraging appropriate antimicrobial use in hospitals is defining what an institution considers appropriate antimicrobial use [7]. Multidisciplinary development of evidence-based treatment guidelines incorporating local microbiology and resistance patterns can improve antimicrobial utilization [21-23]. Guides may sometimes be mere documented procedures, not clinical practice guidelines such as a systematically developed statement designed to assist practitioner and patient to make a decisions about appropriate health care for specific clinical circumstances. The guide for $\mathrm{AB}$ treatment is to assist the treating physician. It cannot, however, release someone from the responsibility of making his/her own decision with due regard for each individual case. These recommendations should be viewed as supplements to the specialized literature. The recommendations of this guide should refer to infections which occur with particular frequency in everyday hospital practice. Rarer diseases are not to be taken into account. The guide for $\mathrm{AB}$ treatment provides indications for therapy (by type of indication, i.e. diagnosis) and the recommended ABs (by brand name and daily dosage). The regimen is divided in primary and alternative. The alternative regimen should cover patients with known $\beta$-lactam allergy. The choice of the AB depends on the established or suspected pathogen, the local in vitro susceptibility pattern, the severity and localization of the infection, contributory clinical factors (e.g. allergy, hepatic and renal function, thrombocytopenia, electrolytes, basic and concomitant diseases, age and pregnancy), the costs of therapy and ecological consequences (e.g. selection pressure and resistance development).

Every department should develop a guide for AB treatment, appropriate for its particular needs (type of infections), based on the template provided. The guide should be reviewed periodically and compliance with the guide should be audited. The members of the various professional groups in a hospital will interpret the binding character of documents containing medical specifications in different ways. With respect to the acceptance of the guide, it is therefore important to make sure that key players of the affected disciplines are involved in the decision making. ESGAP requests: 'Treatment guidelines should cover both hospital and community, should be readily accessible, drawn up with multidisciplinary prescriber involvement, subject to peer review, evidence based where possible and compatible with national guidelines, where these have been adopted' [20].

\section{Guide for Surgical Prophylaxis}

Multidisciplinary development of evidence-based prophylaxis guidelines incorporating local microbiology and resistance patterns can improve antimicrobial utilization [24]. The aim of the $A B$ prophylaxis is to reduce the risk of surgical site infections. Minimization of the intraoperative germ load is meant to prevent infection developing as a result of intraoperative contamination of the surgical site. Every surgical department can develop a guide for surgical prophylaxis, appropriate for its particular needs (type of surgery), based on the attached surgical prophylaxis template (fig. 1). The guide should constitute an agreed standard of procedure and address the five following principles: The prophylactic $\mathrm{AB}$ should be given for a short duration only. The ABs selected for this indication should not be used therapeutically. The ABs selected should not readily lead to emergence of microbial resistance. The ABs used for surgical prophylaxis should be relatively free of side effects and relatively cheap.

The guide for surgical prophylaxis provides the indications for prophylaxis (by type of surgery) and the recommended ABs (by brand name and dosage). The regimens are classified as primary and alternative ones. Typically, first-line substances will be $\beta$-lactam ABs (e.g. 1 st- or 2 nd-generation cephalosporins). For patients with known $\beta$-lactam allergy, alternative substances have to 


\begin{tabular}{|c|c|c|c|c|c|c|c|c|c|}
\hline \multirow{3}{*}{$\begin{array}{l}\text { Indication } \\
\text { (by type of } \\
\text { surgery) }\end{array}$} & \multicolumn{9}{|c|}{ Suggested regimen } \\
\hline & \multirow{2}{*}{$\begin{array}{l}\text { time of } \\
\text { first } \\
\text { application }\end{array}$} & \multicolumn{3}{|c|}{ primary } & \multicolumn{3}{|c|}{ alternative } & \multirow{2}{*}{$\begin{array}{l}\text { duration of } \\
\text { prophylaxis }\end{array}$} & \multirow{2}{*}{ comment } \\
\hline & & $\begin{array}{l}\text { brand } \\
\text { name }\end{array}$ & dosage & $\begin{array}{l}\text { re-dosing } \\
\text { (intra- } \\
\text { operatively) }\end{array}$ & $\begin{array}{l}\text { brand } \\
\text { name }\end{array}$ & dosage & $\begin{array}{l}\text { re-dosing } \\
\text { (intra- } \\
\text { operatively) }\end{array}$ & & \\
\hline & & & & & & & & & \\
\hline & & & & & & & & & \\
\hline & & & & & & & & & \\
\hline & & & & & & & & & \\
\hline
\end{tabular}

Fig. 1. Surgical prophylaxis template.

be listed, too. The guide should include the optimal time of application (e.g. $30 \mathrm{~min}$ before incision), address intraoperative redosing (e.g. if duration of surgery is over twice the half-life of the $\mathrm{AB}$ or major blood loss) and allow comments.

The guide should be reviewed periodically and compliance with the guide should be audited. With respect to the acceptance of the guide, it is important to make sure that key players of the surgical disciplines are involved in the decision making. ESGAP requests: 'Single dose surgical prophylaxis should be encouraged.' The first evidence-based guideline in surgical prophylaxis with a full description of methodology used is available on www. sign.ac.uk or directly from the Royal College of Physicians in Edinburgh [24]. It advocates single-dose prophylaxis for six types of infection and gives advice on how to make local decisions on the need for prophylaxis in areas of debate such as the vast majority of clean, non-implant surgery.

\section{Tools to Analyze Consumption Data}

Extracting antimicrobial use data from pharmacy databases should allow monitoring of antimicrobial use within an institution. Consumption data are valuable for identifying areas (e.g. specific antimicrobials or hospital wards) that require special attention and for monitoring the effects of interventions [8, 25-27]. Another use for antimicrobial consumption data is in cross-institutional benchmarking. Comparing standardized measures of antimicrobial use among hospitals should allow hospitals to determine where they stand in comparison to their peer institutions. Standardizing the units of measurement of antimicrobials (e.g. defined daily doses) can be achieved using the $\mathrm{AB}$ Consumption Calculator (ABC Calc), a tool to be installed in participating hospitals of ABS International [28]. Prospective audit of antimicrobial use with direct interaction and feedback to the pre- scriber can result in reduced inappropriate use of antimicrobials [8]. Formulary restriction and preauthorization requirements can lead to immediate and significant reductions in antimicrobial use and cost and may be beneficial as part of a multifaceted response to nosocomial outbreaks of infection. In institutions that use preauthorization to limit the use of selected antimicrobials, monitoring overall trends in antimicrobial use is necessary to assess and respond to such shifts in use. ESGAP requests: 'Measurement of antibiotic consumption should be performed with regular benchmarking of figures and discussion between prescribers, pharmacists and infection specialists' [20].

\section{AB-Related Organization (AB Officer or AB Management Team)}

Essential to a successful antimicrobial stewardship program is the presence of at least one trained physician who dedicates a portion of his/her time to the design, implementation and function of the program. Supervision by an $\mathrm{AB}$ officer or $\mathrm{AB}$ management team is necessary to ensure that therapeutic and prophylactic guides, antimicrobial restriction policies or other measures are based on the best evidence and practice and will not put patients at risk. Having the program led by an infectious diseases specialist would be desirable, but smaller, nonteaching hospitals in Europe usually lack the personnel $[29,30]$. In this regard, the AB officer should negotiate with hospital administration to obtain adequate authority, time, budget and compensation for the program. The role of the $A B$ officer is described in table 1. Pharmacists often act as the effectors for antimicrobial stewardship programs [31]. They are well positioned because of their role in processing medication orders and their familiarity with the hospital formulary. Clinical pharmacists 
with specialized training in infectious diseases are increasingly seen in the United States. The clinical microbiologist is another key component in the function of antimicrobial stewardship programs. Timely and accurate reporting of microbiology susceptibility test results allows selection of more appropriate and focused therapy, and may help reduce broad-spectrum antimicrobial use. The $\mathrm{AB}$ officer and the $\mathrm{AB}$ management team need to decide what strategies their stewardship program will use to improve antimicrobial use. This decision must take into account the size of the hospital, intensity of antimicrobial use in the patient population, sophistication of the hospital information system and personnel available. Restriction strategies are effective at controlling use but raise issues of prescriber autonomy and require a large personnel commitment. Review and feedback strategies are promising but also usually require dedicated personnel. Passive educational strategies are easiest to implement but often ineffective. Whatever the choice of strategies, the involvement of all affected parties should be sought early in the process to ensure acceptance of the program. ESGAP requests: 'A multi-disciplinary antibiotic team should be created and empowered to act to control injudicious use of antibiotics. The role of multi-disciplinary antibiotic teams and infectious disease pharmacists needs to be explored further' [20].

Collaboration between the $\mathrm{AB}$ officer or $\mathrm{AB}$ management team and the hospital infection control and pharmacy and therapeutic committees or their equivalents is essential [8].

\section{Conclusions}

Reducing the use of antimicrobials to only those situations where they are warranted, at the proper dose and for the proper duration, is the prerequisite for sustainable control of antimicrobial resistance. Physicians are primarily concerned with the effects of antimicrobials on the individual patients in their care, not about the risk of contributing to the problem of antimicrobial resistance in society [32]. Therefore, mere publication of evidencebased practice guidelines regarding antimicrobial use is insufficient to significantly impact antimicrobial prescribing patterns in a given hospital. Adaptation to local circumstances, collaboration with local specialists and active involvement of hospital staff are required to increase the chances of the adoption of such recommendations in clinical practice. Education alone, without incorporating active intervention, is only marginally effective
Table 1. Description of the AB officer's role

Objectives

Continuous performance of $\mathrm{AB}$ stewardship functions in the hospital

\section{Organizational Position}

Reports to the medical director

Is a member of the drug committee

Is a member of the $\mathrm{AB}$ management team of the hospital

Participates in departmental meetings on antibiotic prophylaxis and therapy

Coordinates the departmental $\mathrm{AB}$ contact persons

Is a consulting physician and/or advisor on antibiotic issues

\section{Tasks}

Is the central contact person for AB-related issues in a hospital

Develops and adapts the $\mathrm{AB}$ tools for the hospital in cooperation with departmental $A B$ contact persons and the pharmacist with special responsibility for $\mathrm{AB}$

Coordinates the development of departmental $\mathrm{AB}$ therapy guides

Organizes information workshops on and training in antibiotic therapy

Works together with the pharmacist with special responsibility for $\mathrm{AB}$ to analyze consumption of antibiotics

Submits antibiotic issues to the drug committee

Advises individual patients on antibiotic issues

Formal responsibilities

Developing and updating $\mathrm{AB}$ tools, such as the $\mathrm{AB}$ list, guides for $\mathrm{AB}$ prophylaxis, for example

\author{
Qualifications \\ At least 6 years of professional experience as a practicing \\ physician \\ Special qualifications in infectious diseases, communication \\ skills, management and information technology
}

in changing antimicrobial-prescribing practices and has not demonstrated a sustained impact [8]. The project ABS International aims to provide the basic tools for implementing $A B$ stewardship and to install them in approximately 40 European hospitals. Process measures (Did the intervention result in the desired change in antimicrobial use?) and outcome measures (Did the process implemented reduce or prevent resistance or other unintended consequences of antimicrobial use?) are necessary to finally determine the impact of antimicrobial stewardship on antimicrobial use and resistance patterns [8]. Valid process measures as well as quality indicators for $\mathrm{AB}$ use will be developed within the project 'implementing $\mathrm{AB}$ strategies for appropriate use of $\mathrm{ABs}$ in hospitals in member states of the European Union - ABS International'. None of the efforts of physicians, pharmacists, microbiologists or infection control practitioners to es- 
tablish an antimicrobial stewardship program are likely to be successful without at least passive endorsement by hospital leadership [7]. The support and collaboration of hospital administrators, medical staff leaders and local providers in the development and maintenance of an antimicrobial stewardship program is an essential prerequisite to the success of the program. Identification and control of antimicrobial resistance and maintenance of $\mathrm{AB}$ effectiveness as the key goals of each individual hospital are important in supporting the efforts of antimicrobial stewardship teams. The problem of antimicrobial resistance cannot be addressed by national initiatives alone, but requires a common strategy at the European level [33]. ABS International is the first EU-funded initiative focusing on the implementation of structural measures in hospitals to promote the prudent use of $\mathrm{ABs}$.

\section{Appendix: Members of ABS International}

Roland Gareis, ABS Group, Vienna (Austria); Reli Mechtler, Johannes Kepler University, Linz (Austria); Marc Struelens, University of Brussels (Belgium); Vlastimil Jindrak, Na Homolce Hospital Prague (Czech Republic); Winfried Kern, University Hospital of Freiburg (Germany); Gabor Ternak, University of Pecs (Hungary); Giuseppe Cornaglia, Università degli Studi di Verona (Italy); Waleria Hryniewicz, National Medicines Institute, Warsaw (Poland); Vladimir Krcmery, St. Elisabeth University of Health and Social Sciences, Bratislava (Slovakia); Milan Cizman, University Medical Center Ljubljana (Slovenia), and Vahe Kazandjian, Center of Performance Studies, Baltimore, Md. (USA).

\section{References}

1 McLoughlin A, O'Morain C: Effectiveness of antiinfectives. Chemotherapy 2005;51:243246.

2 Raveh D, Yinnon AM, Broide E, Rudensky B: Susceptibilities of ESCL-producing Enterobacteriaceae to ertapenem, meropenem and piperacillin-tazobactam with and without clavulanic acid. Chemotherapy 2007;53: 185-189.

- 3 Tenover FC, Hughes JM: The challenges of emerging infectious diseases. Development and spread of multiply-resistant bacterial pathogens. JAMA 1996;275:300-304.

4 Wise R: Antimicrobial resistance: paradox, actions and economics. J Antimicrob Chemother 2006;57:1189-1196.

5 Anonymous: Council Recommendation of 15 November 2001 on the prudent use of antimicrobial agents in human medicine (2002/77/EC). OJEU 2002;45:13-16.

6 Gould IM: Stewardship of antibiotic use and resistance surveillance: the international scene. J Hosp Infect 1999;43:S253-S260.

-7 MacDougall C, Polk ER: Antimicrobial Stewardship Programs in Health Care Systems. Clin Microbiol Rev 2005;18:638-656.

-8 Dellit TH, Owens RC, McGowan JE, Gerding DN, Weinstein RA, Burke JP, Huskins WC, Paterson DL, Fishman NO, Carpenter CF, Brennan PJ, Billeter M, Hooton TM: Infectious Diseases Society of America and the Society for Healthcare Epidemiology of America guidelines for developing an institutional program to enhance antimicrobial stewardship. Clin Infect Dis 2007:44:159177.
9 Allerberger F, Gareis R, Janata O, Koller W, Lechner A, Mittermayer H, Pecnik I, Reisinger E, Rotter-leBeau M, Wechsler-Fördös A, Zuchi D: ABS Projekt Leitlinien zur Weiterentwicklung der Antibiotika-Kultur in Krankenanstalten. Vienna, Bundesministerium für Arbeit, Gesundheit und Soziales, 1998.

10 Allerberger F, Gareis R, Janata O, Koller W, Lechner A, Mittermayer H, Pecnik L, Reisinger E, Rotter-leBeau M, Wechsler-Fördös A, Zuchi D: The ABS Project: guidelines to further develop and define antibiotic use in hospitals. Vienna, Federal Ministry for Social Security and Generations, 2000, www. antibiotika-strategien.at.

11 Allerberger F, Gareis R, Janata O, Krause R, Meusburger S, Mittermayer H, Rotter-leBeau M, Watschinger R, Wechsler-Fördös A: ABS Projekt Leitlinien zur Weiterentwicklung der Antibiotika-Kultur in Krankenanstalten. ed 2, revised. Vienna, Bundesministerium für soziale Sicherheit und Generationen, 2002.

12 Woodward RS, Medoff G, Smith MD, Gray JL: Antibiotic cost savings from formulary restrictions and physician monitoring in a medical-school-affiliated hospital. Am J Med 1987;83:817-823.

13 Coleman RW, Rodondi LC, Kaubisch S, Granzella NB, O’Hanley PD: Cost-effectiveness of prospective and continuous parenteral antibiotic control: experience at the Palo Alto Veterans Affairs Medical Center from 1987 to 1989. Am J Med 1991;90:439444.

14 Maswoswe JJ, Okpara AU: Enforcing a policy for restricting antimicrobial drug use. Am J Health Syst Pharm 1995;52:1433-1435.
15 White AC, Atmar RL, Wilson J, Cate TR, Stager CE, Greenberg SB: Effects of requiring prior authorization for selected antimicrobials: expenditures, susceptibilities, and clinical outcomes. Clin Infect Dis 1997;25: 230-239.

16 MacKenzie FM, Monnet DL, Gould IM, ARPAC Steering Group: Relationship between the number of different antibiotics used and the total use of antibiotics in European hospitals. J Antimicrob Chemother 2006;58: 657-660.

17 May AK, Melton SM, McGwin G, Cross JM Moser SA, Rue LW: Reduction of vancomycin-resistant enterococcal infections by limitation of broad-spectrum cephalosporin use in a trauma and burn intensive care unit. Shock 2000;14:259-264.

18 Anatomical therapeutic chemical (ATC) classification index with defined daily doses (DDDs). Oslo, WHO Collaborating Center for Drug Statistics Methodology, 2005, http://www.whocc.no/atcddd/ or http:// www.escmid.org/sites/index f.aspx?par $=2.5$

19 White AC, Atmar RL, Wilson J, Cate TR, Stager CE, Greenberg SB: Effects of requiring prior authorization for selected antimicrobials: expenditures, susceptibilities, and clinical outcomes. Clin Infect Dis 1997;25: 230-239.

20 Gould IM: Minimum antibiotic stewardship measures. Clin Microbiol Infect 2001;7 (suppl 6):22-26.

21 Holmes WF: Conflicts of interest between the prescriber, the regulator and the profit maker. Clin Microbiol Infect 2001;7(suppl 6):9-11. 
22 Marrie TJ, Lau CY, Wheeler SL, Wong CJ, Vandervoort MK, Feagan BG: A controlled trial of a critical pathway for treatment of community-acquired pneumonia. JAMA 2000;283:749-755.

-23 Price J, Ekleberry A, Grover A, Melendy S, Baddam K, McMahon J, Villalba M, Johnson M, Zervos MJ: Evaluation of clinical practice guidelines on outcome of infection in patients in the surgical intensive care unit. Crit Care Med 1999;27:2118-2124.

24 Scottish Intercollegiate Guideline Network: Antibiotic Prophylaxis in Surgery. A National Clinical Guideline. Edinburgh, SIGN, 2000, SIGN Pub No 45.

25 Madaras-Kelly K: Optimizing antibiotic use in hospitals: the role of population-based antibiotic surveillance in limiting antibiotic resistance. Insights from the society of infectious diseases pharmacists. Pharmacotherapy $2003 ; 23: 1627-1673$.
26 Interagency Task Force on Antimicrobial Resistance: A public health action plan to combat antimicrobial resistance. I. Domestic issues. Atlanta, Centers for Disease Control and Prevention, 2001, pp 1-43, http:// www.cdc.gov/drugresistance/actionplan/ index.htm.

27 Shlaes DM, Gerding DN, John JF Jr, Craig WA, Bornstein DL, Duncan RA, Eckman MR, Farrer WE, Greene WH, Lorian V, Levy S, McGowan JE Jr, Paul SM, Ruskin J, Tenover FC, Watanakunakorn C: Society for Health Care Epidemiology of America and Infectious Diseases Society of America Joint Committee on the Prevention of Antimicrobial Resistance: guidelines for the prevention of antimicrobial resistance in hospitals. Clin Infect Dis 1997;25:584-599.

28 Monnet DL: ABC Calc - Antibiotic consumption calculator [Microsoft ${ }^{\circledR}$ Excel application], version 3.0. Copenhagen, Statens Serum Institute, 2005, http://www.ssi.dk/ sw379.asp.
29 Gross R, Morgan AS, Kinky DE, Weiner M, Gibson GA, Fishman NO: Impact of a hospital-based antimicrobial management program on clinical and economic outcomes. Clin Infect Dis 2001;33:289-295.

30 Struelens MJ: Multidisciplinary antimicrobial management teams: the way forward to control antimicrobial resistance in hospitals. Curr Opin Infect Dis 2003;16:305-307.

31 Rybak MJ: Antimicrobial stewardship. Pharmacotherapy 2007;27:131S-135S.

32 Metlay JP, Shea JA, Crossette LB, Asch DA: Tensions in antibiotic prescribing: pitting social concerns against the interests of individual patients. J Gen Intern Med 2002; 17: 87-94.

33 Bronzwaer S, Lönnroth A, Haigh R: The European Community strategy against antimicrobial resistance. Euro Surveill 2004;9:3034. 